\title{
The Native Language In Teaching Kindergarten Mathematics
}

\author{
Janet P. Espada, Ph.D., Leyte Normal University, Philippines
}

\begin{abstract}
The use of the native language as a medium of instruction is believed to be the fastest and most natural route towards developing a strong foundation in mathematics literacy (Mimaropa, In D.O.No. 74, s.2009). This study examined the effect of using the native language in the teaching of kindergarten mathematics. A total of 34 five to six year old children went through a pretestposttest, quasi-experimental study with 17 participants in each of the control or English group and the native language (Waray) or experimental group, respectively. It was assumed that the use of the native language would increase academic performance in mathematics. Findings revealed a highly significant difference between the mean gain of the control and experimental groups ( $p$ value $=.000$ ) indicating that the level of mathematics performance of the experimental group was significantly higher than that of the control group. The result implies that the kindergarten pupils exposed to the native language performed better in mathematics than those who were exposed to English. The study concludes that the use of the native language in teaching kindergarten mathematics results in a higher mathematics performance than the use of a foreign language as a medium of instruction.
\end{abstract}

Keywords: Native Language Teaching; Teaching Kindergarten Mathematics

\section{INTRODUCTION}

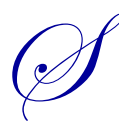

tudies (Walter, et.al., 2010; Dekker, P.G.,1999) show that the best time to use the native language is when the children first enter school (i.e., kindergarten); a time when they usually think and process in their own mother tongue. Moreover, researches confirm that students who speak their home language attain higher mathematics and science achievement (Nolasco, 2010:86). In international math competitions, the high performing countries are those that allow their students to use their home language (Azurin, 2010:5). A corpus of recent studies and literature (Bernardo, 1999; 2001; Dekker, D.,1999; 2003; 2010;Baguingan, 2000; Arzadon, 2010;Azurin, 2010; Limjap, 1999; Reyes, 2000: Luz, 2010; Nolasco,2010; Licuanan,2010) would support the idea that the use of the first language creates a smoother path for the young learner to understand and acquire basic math concepts, knowledge and skills.

However, many children in the Philippines today study mathematics in a language they don't understand. Young (2003: 126) notes that the mother tongue of most Filipino children is neither Filipino nor English. Using these languages may help the child carry out basic functions in his own contextual milieu but this may also impede both cognitive and non-cognitive areas such as school attendance, self-concept, self-esteem, social and emotional adjustment, and moral development (Dekker, 1999). To a child who neither uses English at home nor at play with his/her friends, English is totally a foreign language. Listening to the strange sound and accent of the words may at first enchant the child but as the lesson becomes cognitively demanding he begins to feel disillusioned. The language barrier consequently stores up episodes of communication breakdowns between the teacher and the child; between the child and the unknown concept. Daunted by the feeling of not being able to communicate well in the foreign language, the child eventually drops out of school. In Young's terms, many children today leave school too early because the language of instruction has failed to facilitate their learning (2003:126).

It should be noted, however, that the choice of the language of instruction does not solely depend on the educational goals and instructional processes. The educational, instructional, and learning processes comprise a 
complex interrelated system of knowledge and processing components which influence a multilingual person's language proficiencies in different ways. Since there exists a multiple representation of knowledge, various activities in different contexts may also require different languages (Bernardo, 1999: in press). For example, in a study of the differential effects of mathematical ability and language use on computational and conceptual knowledge of descriptive statistics which tested bilingual learners, Reyes (2000:8) found that the first language facilitated performance in the area of conceptual knowledge but not in computational knowledge. Similarly, a number of studies conducted by Bernardo (1999, in press) disclosed that in terms of understanding word problems, the bilingual students were more effective when they used their first and more proficient language. Contrastingly, the students incurred more errors in comprehension when the problems were in their second language. Nonetheless, language was not found to be a determinant in the abstraction process which required the application of mathematical principles in solving the problem. The important point to grasp in both experiments is the fact that the first language can be most functional in the contextual perception of word problems but not the process of solving the problems. Since kindergarten math requires the teaching of the basic concepts, it would be most helpful for the children to use their home language.

The common problem of facilitating mathematics learning is likewise connected to the language of instruction. For instance, Copeland (1984:359) noted that when children do badly in math, it is because they don't understand the lessons, not the subject. Copeland contends that the child's inability to cope with math is due to the excessively rapid passage from the qualitative (logical) to the quantitative (numerical). This rapid passage involves a complex course of actions, such as, learning new knowledge and skills; active construction of meaning; control and monitoring of one's own process of understanding; physical, social and cultural context of the learning task, and the children's individual differences. Learning new concepts requires the transformation and/or reorganization of existing prior knowledge and representation. Such prior knowledge pattern and insights are acquired in the home and community and incorporated in the learners' first language (L1) or mother tongue. To thrust aside the use of L1 upon the child's entry into school is akin to dislodging their prior or foundational knowledge from the learning processes and concepts in the classroom (Azurin, 2010:4, 5; Walter, 1991:213).

In order to actively construct meaning, math learning should be experience-oriented. (Copeland, 1984:4) Active means using two senses. One is acting on material things while the other means doing things in collaborative or group effort. This process leads to a critical frame of mind, where children must convey their ideas in their most proficient language. A number of studies in mathematical problem solving have shown that when the students are actively engaged in problem information, they are better able to understand and solve the problem (Bernardo, 2000:123). Controlling one's own process of understanding may be done through free investigation and spontaneous effort. The teacher, therefore, provides a rich physical environment and encourages the child to experiment, but realizes the difference between physical knowledge which can be discovered and logicomathematical knowledge which may have to be invented (Copeland, 1984:365). The process of investigation and invention of knowledge necessitates the use of a language where children may freely and spontaneously ask or answer questions or discuss observations with the teacher and with peers.

As the learning process is influenced by the physical, social and cultural context of the learning task, the quality of interactions between the child and the significant others around him would be affected by the language of communication at home, in school and in the community. Studies have proven that the use of the mother tongue creates a sense of pride in having to use one's home language; thus, elevating the young child's self-esteem and eliminating his fears and inhibitions (Arzadon, 2010:13). Each child in the classroom conveys a unique set of prior knowledge, interests, motivations, personality, and learning styles. Children should, therefore, be allowed to construct, explore, and critique their own knowledge in an environment where there is a free flow of ideas and where both the good ones and the low-performing pupils have the opportunity to participate actively in the learning process.

The aforementioned views strongly point to the native language as an effective tool in solving one of the country's major ailments- the continuous decline in mathematics education. Mathematics is an important weapon in every nation's global, scientific, and technological development. However, very few studies have been conducted in the area of language and its influence on kindergarten mathematics. It is assumed that the earlier the child builds a strong foundation in math learning, the better will he perform math in later years. Emphasis should therefore be placed on early childhood math studies. 
It is in this framework that the present study was conducted. This study examined the effect of using the native language in teaching mathematics to kindergarten pupils in the public schools where the native language is Waray, categorized by Sibayan (1999:5) as a major language in one of the regions in the Philippines. It specifically attempted to determine whether there was a significant difference in the mathematics performance of pupils who used their native language and those who used a foreign language.

\section{METHOD}

\section{Design and Procedure}

A pretest-posttest nonequivalent group quasi-experimental design was used because the children were grouped heterogeneously and for which random selection and assignment was not possible. The two sections had unequal number of boys and girls with prior knowledge in math in varying degrees. The design allowed the researcher to compare the results obtained from the experimental group against the control group with the use of the native language as the independent variable whose effect was being tested. This method involved the use of a pretest and a posttest.

\section{Subjects}

Thirty-four (34) five to six year old kindergarten pupils in a public school from an interior barangay were divided into two classes with 17 pupils in each section. Despite the heterogeneous grouping, some characteristics were comparable in terms of age, socio-economic status, place of origin, level of literacy, and home language which is Waray. The same mathematics teacher handled the two classes in order to maintain a similar teaching pedagogy, level of competence, and utility of instructional materials. This was also done to compare behavior patterns and responses between the two groups as they used their designated language of instruction. The afternoon class was assigned as the experimental group who received instruction in the native language. The morning class, taught in English, served as the control group.

\section{Content, Strategy, Materials}

The study dealt with the basics in kindergarten math as follows: counting up to 10; comparing; patterns; addition; subtraction; positions; fractions; time; sorting; ordering and classifying; measurement; geometry; and analysis of data in graphs. These concepts build the child's foundation for conceptual and logico-mathematical skills. The strategy used in teaching was based on the Mother Tongue-Based Multilingual Education (MTBMLE) Program, a new pedagogy that enables learners to participate actively in classroom activities through the use of the first language (Dekker, D. 2010:23). Featuring literacy, prior knowledge, cognitive development and higher order thinking skills (HOTS), strong bridge, scaffolding, and teaching for meaning and accuracy, the MTBMLE targets on helping children become confident thinkers who are able to cope with the demands of literacy.

Except for the language of instruction and materials, the teacher used the same procedure, techniques and materials content in both classes. The daily lesson started with a focusing activity that varied from day to day, depending on the lesson's objectives. The development of the lesson included a creative presentation of the concept utilizing both concrete and abstract materials, group dynamics, pictures, and other math manipulatives. To test whether the concept had been understood, varied exercises using the same materials were provided; the last part of which was answering about five (5) exercises using written numbers and graphics. The teacher then gave a recap, followed by the generalization of the concept done by the pupils. The lesson ended with a written evaluation and a discussion of the correct answers. The English group received more comprehensible input in explaining the concepts since the children were being exposed to a foreign language for the first time and the teacher did not resort to translation.

\section{Instruments}

The pretest/posttest comprising 37 items testing 37 basic skills in kindergarten mathematics included numbers and counting up to 10; comparing; patterns; addition; subtraction; positions; fractions; time; sorting, ordering, and 
classifying; measurement; money; geometry; and data and graphs. Each skill had one item to be tested using numbers, pictures and a range of graphical presentations. Its purpose was to determine both the control and experimental groups' level of mathematics performance; their mean gain from pretest to posttest; and mean difference between the two groups. The test was tried out on a bigger number of kindergarten pupils not involved in the study, tested for reliability with a coefficient of 1.00 using Kuder-Richardson 20, and then examined and confirmed by math specialists.

\section{Statistical Treatment}

Three types of T-Tests served as statistical tools: the One -Sample T-Test to determine the pre-posttest levels in math of both control and experimental groups; the T-Test for Dependent Means to find the Pre-Posttest mean gain difference in both groups; and the T-Test for Independent Means to verify whether there was a significant mean gain difference between the pupils exposed to the foreign language and those exposed to the native language. If it occurred that the experimental group's mean gain was higher than that of the control group, then there would be sufficient evidence to conclude that the use of the native language in teaching kindergarten mathematics proved to be more effective than the use of a foreign language.

\section{RESULTS AND DISCUSSION}

This section answers the questions posed in this study. The results of the experiment are presented and statistical analyses are provided to validate the hypotheses that were formulated.

\section{Pre/Posttest Levels of Mathematics Performance}

Table 1 provides a full picture of how each of the control and experimental group fared against the hypothetical or standard mean in the pretest and posttest. The hypothetical mean in this study was 22.2 or $60 \%$ of 37 , the total number of items in the pre /posttest. Results of the pretest suggest that both groups failed to meet the hypothetical mean of 22.2. Attributed to this poor result could be the fact that the pupils did not possess conceptual knowledge in most of the competencies being tested. Although the experimental group obtained a higher mean than the control group it was still below the passing mean; thus, the results could be comparable since they specify that the entry points of both groups before the treatment were of the same level (i.e., below average). It is, therefore, stressed that the conduct of the experiment was devoid of bias.

The posttest results disclosed a difference in the actual means of the two classes. Compared to the control group who only attained a mean score considered to be a little below average ( $M=20.6)$, the experimental group obtained a higher mean score $(\mathrm{M}=31.2)$ which is above average. This finding suggests that in using a language they understood well, the Waray group was able to gain superior mathematics literacy faster than their counterparts who studied math in a foreign language (English). Wong and Snow (2000: 5) found that children develop oral proficiency first in their native language which functions as foundation for literacy and means of learning in school. Using their home language in interacting with math, the experimental group may have understood the concepts without much effort. This confirms the notion that "as competency in a language increases, deductive reasoning skills in mathematics also increases" (Baker, 1996, in Dekker, 2003:45).

The failure of the English group may be attributed to limited English proficiency. The children were placed in a tremendous pressure to learn mathematics using a language strange to them. They displayed very little interest especially in skills which required more abstractions. Thus, despite the application of comprehensible input, the learners still fell short of reaching a satisfactory level of performance in the posttest. This finding is supported by some studies (Acuña, 1994; Dekker, 2003; Tucker, 1996; Thomas and Collier,2000) asserting that the use of a foreign language as a medium of instruction delays cognitive development resulting in poor performance, low confidence level, self-concept and self-esteem. 


\section{Pre-Post Mean Gain Difference of the Control and Experimental Groups}

Table 2 summarizes the data that illustrates whether each group benefited from the treatment or not. The result signifies that both English and Waray groups achieved a notable improvement from the pretest to the posttest. In the course of the experiment, the teacher utilized comprehensible input (i.e., use of hand and body language, gestures, words, pictures, real objects, songs, and the like) in assisting the pupils' comprehension of math concepts. This factor may have caused the remarkable increase in their posttest results.

Table 1. Level of mathematics performance

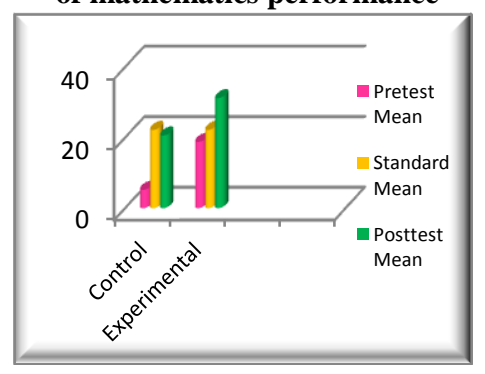

Table 2. Pretest/Posttest mean gain difference

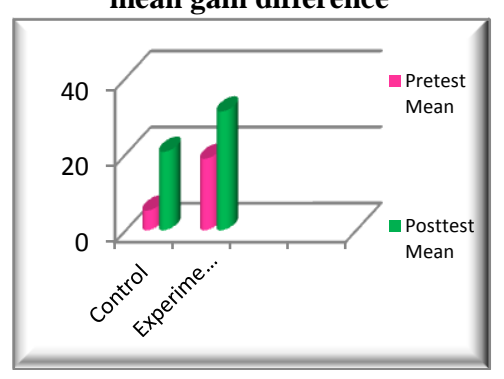

Table 3. Mean gain difference between 2 groups

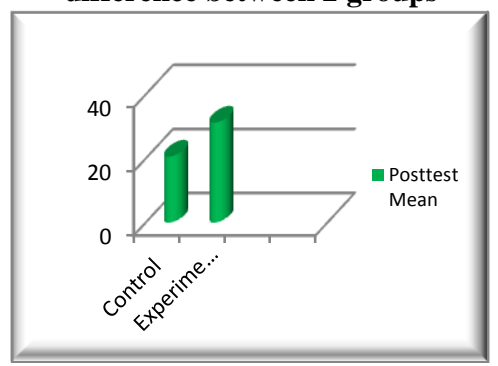

The results show that the mean gain obtained by the experimental group is lower than the control group. This may be due to the fact that the experimental group already attained a high mean score in the pretest $(\mathrm{M}=18.8)$; thus, there was a narrower gap between the pretest and the posttest. It is likewise observable that the English group took a strong leap from a mean score of 5.2 to 20.6; yet, a deeper probe into their posttest results showed that majority of them could only cope with the lower level skills. Very few were able to handle higher level skills which required deductive reasoning. This result suggests that without proficiency in the language of instruction, even if the children had potentials in math, they were likely to fail because the language barrier has created a wide gap between them and the concepts/skills being studied.

\section{The Difference in the Performance between the Control and Experimental Groups}

Table 3 provides the answer to the main question posed in the study which is to find out which language as medium of instruction in teaching mathematics proved to be more valuable - the foreign or native language. Results indicate that the native language group achieved a higher mean gain $(M=10.65)$ than the foreign language group. With this finding, it may be concluded that the use of the native language which is the home language of the children proved to be more effective in bringing out a higher mathematics achievement than the use of a foreign language.

Apart from the statistical findings, some observations were noted. The English group hardly expressed ideas and answers to questions. They participated in the group activities with little signs of understanding; exhibiting less enjoyment and enthusiasm. Some of these children may have actually possessed a high aptitude in math but because of the language barrier, their progress may have been hindered. In a different picture, the children in the experimental group argued, reacted, posited opinions, and engaged in activities freely. The use of the home language created an ambiance where math anxiety which is generally common among children hardly existed. This observation carries Jameson's (2008) conclusion that in a non-threatening environment, children develop a high level of self-concept which generates more confidence, security and joy.

The present study strongly supports a recent experiment on native language which found that pupils exposed to the mother tongue proved to be superior when tested with skills in certain subjects including mathematics (Alicando, 2002:42). This study likewise confirms the finding of Evangelista (1995:106) that the grade four pupils who studied math using their mother tongue showed very positive results. Alongside significant findings in previous researches (Bernardo, 1999; 2000; 2001; Dekker, D., 1999; 2003; 2010; Dekker, G., 1999; Limjap, 1999; Reyes, 2000; Luz, 2010) it may be concluded that the most basic concepts and literacy skills in mathematics can be taught best in the child's native language. Since the child's early years are the most absorbent, this study strongly 
recommends that the native language be used as language of instruction as early as kindergarten in order to establish a solid foundation not only in mathematics but also in other areas.

A limitation in the present study would be the fact that the respondents came from the same school. Replicating the study in a wider scale involving both public and private schools in the whole district or city may generate similar or varied results in comparison with the present study. Another prospect for future study could also be an examination on the effect of the native language in the teaching of other subjects such as science, social studies, music, and other areas of learning. By and large, the strength of the study lies in establishing the benefit of the native language as a powerful tool in the teaching and learning of both basic and advanced skills in kindergarten mathematics. Using the first language enables learners to interact, investigate, and invent knowledge; thus, maximizing the learners' full potential and allowing them to build up logic at an early age. If language proficiency is viewed as an index of intellectual competence, it can, therefore, be said that the more a person is proficient in the language of instruction, the more chances he has in achieving academic success.

\section{ACKNOWLEDGEMENTS}

This paper was supported in part by Dr. Manuel R. Espina, my mentor; Dr. Allan B.I. Bernardo who furnished valuable articles and information; and Leyte Normal University through Dr. Evelyn C. Cruzada who funded this project.

\section{AUTHOR INFORMATION}

Janet Presnilla-Espada has completed a BEEd in English; MAT in Language Teaching; Ph.D in Educational Programs Management; Certificate in Montessori Education; and MAEd in Early Childhood Education. She is currently an Assistant Professor of the Leyte Normal University, Philippines and her professional interests include language teaching, professional and early childhood education. She wrote a kindergarten mathematics workbook in two languages: the mother tongue (Waray) and the second language (English). E-mail: janetpresnilla2007@yahoo.com

\section{REFERENCES}

1. Acuña, J.E. (1994). Language of instruction in science education. The Language Issue in Education. Congressional Oversight Committee on Education. Quezon City: Congress of the Republic of the Philippines. 87-118.

2. Alicando, G. S. (2002). Medium of instruction and retention of science and mathematics concepts of grade three pupils. Unpublished Master's Thesis, Leyte Normal University, 23-42

3. Arzadon, C. (2010). Dedicated to cause greater than themselves. In Nolasco, R.M.D., Datar, F.A., Azurin, A.M. (Eds.) Starting Where the Children Are: A Collection of Essays on Mother Tongue-Based Multilingual Education and Language Issues in the Philippines, Quezon City:170+Talaytayan MLE Inc., 12-17.

4. Azurin,A. M. (2010). Reinventing basic education: the shift to mother tongue-based instruction. In Nolasco, R.M.D., Datar, F.A.,Azurin, A.M. (Eds.) Starting where the Children Are: A Collection of Essays on Mother Tongue-Based Multilingual Education and Language Issues in the Philippines, Quezon City:170+Talaytayan MLE Inc., 1-6.

5. Baguingan, G.D. (2000). Grassroots legitimacy: the first language component bridging program pilot project of region 2 and car. Philippine Journal of Linguistics, 31(2),93-105.

6. Baker, C. (1996). Foundations of bilingual education and bilingualism ( $2^{\text {nd }}$ edition) Clevedon, England: Multilingual Matters.

7. Bautista, M. L.S. (1999). Bridging research and practice in literacy work among minority language groups in the Philippines. The Asia-Pacific Education Researcher, 8 (2), 111-128.

8. Bernardo, A.B.I. (in press). Language, learning, and medium of instruction in multilingual contexts: An information-processing components perspective. In U.Kim \& Y.-S. Park (Eds.), Asia's educational miracle: Psychological, social, and cultural perspectives. New York: Springer Publishing. (1-12) 
9. Bernardo, A.B.I. (2001). Beyond functional literacy, towards a multiliteracy pedagogy. Philippine Journal of Linguistics, 32 (2), (1-10)

10. Bernardo, A.B.I. (1999). Defining the domains and levels of literacy development for Filipino bilinguals: issues and prospects. In Bautista, M. L. S. and Tan, G.O. (Eds.) The Filipino Bilingual: a multidisciplinary perspective. Linguistic Society of the Philippines, Manila, Philippines. (73-86)

11. Bernardo, A. B. I. (2007). Language in Philippine education: Rethinking old fallacies, exploring new alternatives amidst globalization. In T. R. F. Tupas (Ed.)(Re)making society: The politics of language, discourse and identity in the Philippines (pp. 1-26). Quezon City, Philippines: University of the Philippines Press.

12. Copeland, R. W. (1984). How children learn mathematics: teaching implications of Piaget's research. New York: Macmillan Publishing Company. (359-365)

13. Dekker, D. E. (2010).What is mother tongue-based multilingual education?. In Nolasco, R.M.D., Datar, F.A.,Azurin, A.M. (Eds.) Starting where the Children Are: A Collection of Essays on Mother TongueBased Multilingual Education and Language Issues in the Philippines, Quezon City:170+Talaytayan MLE Inc., (23-25)

14. Dekker, D. E. (1999). Leaving home: my language or yours? In Bautista, M. L.S. and Tan, G.O. (Eds.) The Filipino Bilingual: a multidisciplinary perspective. Linguistic Society of the Philippines, Manila, Philippines. (103-110)

15. Dekker, D. E. (2003). A case study of the first language component bridging program in rural Philippines, Philippine Journal of Linguistics, 34 (1), (143-149)

16. Dekker, G. P. (1999). First language component literacy: a bridge over troubled waters. In Nolasco, R.M.D., Datar, F.A.,Azurin, A.M. (Eds.) Starting where the Children Are: A Collection of Essays on Mother Tongue-Based Multilingual Education and Language Issues in the Philippines, Quezon City:170+Talaytayan MLE Inc., (94-102)

17. Department Order No.107 s. 1989. Standards for the operation of preschools (Kindergarten Level) Retrieved from http://unesdoc.unesco.org/images/0014/001472/147225e.pdf

18. Evangelista, F.A. (1995). Mathematics achievement of grad four pupils using the First Language Component-Bridging Program in Bascaran Elementary School first grading period, SY 1994-1995. M.A. Thesis,Nueva Viscaya Institute of Technology, Bayombong, Nueva Viscaya.

19. Fillmore, L.W., Snow C.E. (2000). What teachers need to know about language. ERIC: Clearing House on Languages and Linguistics, A Special Report, 1-41

20. Jameson, M. M. (2008). Contextual factors related to math anxiety in second grade children. Dissertation Abstracts International, 69 (6), 1523-1524

21. Licuanan, P.B. (2010). Students learn better when the mother tongue is used. In Nolasco, R.M.D., Datar, F.A.,Azurin, A.M. (Eds.) Starting where the Children Are: A Collection of Essays on Mother TongueBased Multilingual Education and Language Issues in the Philippines, Quezon City:170+Talaytayan MLE Inc., 117-121.

22. Limjap, A.A. 1999. Enhancing the deductive reasoning of mathematics teachers in constructivist environment. The Asia-Pacific Education Researcher, 8 (1) , 28-57.

23. Luz, J.M. (2010). 'English first' policy will hurt learning. In Nolasco, R.M.D., Datar, F.A., Azurin, A.M. (Eds.) Starting where the Children Are: A Collection of Essays on Mother Tongue-Based Multilingual Education and Language Issues in the Philippines, Quezon City:170+Talaytayan MLE Inc., 81-84.

24. Nolasco, M.D.N. (2010). Fixing education through language. In Nolasco, R.M.D., Datar, F.A.,Azurin, A.M. (Eds.) Starting where the Children Are: A Collection of Essays on Mother Tongue-Based Multilingual Education and Language Issues in the Philippines, Quezon City:170+Talaytayan MLE Inc., 85-87.

25. Pascasio, E. M. (2000). An update on the language behavior profile of the Filipino bilingual: correlates of language proficiency. Philippine Journal of Linguistics, 31 (1). 11-24.

26. Reyes, M. L. (2000). Differential effects of mathematical ability and language use on computational and conceptual knowledge of descriptive statistics. The Asia-Pacific Education Researcher, 9 (1), 83-115.

27. Thomas, W.P. \& Collier, V.P. A national study of school effectiveness for language minority students' long-term academic achievement final report:project1.1. Retrieved from http://www.crede.ucsc.edu/research////llaa/1.1_final.html 
28. Tucker, G.R. (1996). Some thoughts concerning innovative language education programmes. Journal of Multilingual and Multicultural Development, 17 (2-4), 315-320.

29. Walter, G.S.(1991). Degree of bilingualism and arithmetic problem solving in Hispanic first graders. The Elementary School Journal, 92(2), 213-231.

30. Young, C. (2003). First language: a foundation for effective basic Education. Philippine Journal of Linguistics, 34 (1), 123-131. 